\title{
Karakterisasi Derajat Kejenuhan Tanah Berdasarkan Pendekatan Logaritma Potensial Kapiler (pF)
}

\author{
Aris Rinaldi ${ }^{1}$, Reza Adhi Fajar ${ }^{2}$ \& Lilik Eko Widodo ${ }^{3}$ \\ ${ }^{1}$ Mahasiswa Magister Program Studi Teknik Air Tanah, \\ Institut Teknologi Bandung \\ ${ }^{2}$ Mahasiswa Doktor Program Studi Rekayasa Pertambangan, \\ Institut Teknologi Bandung \\ ${ }^{3}$ Staf Pengajar Program Studi Teknik Pertambangan dan Teknik Air Tanah, \\ Institut Teknologi Bandung \\ Email: aris.itb@gmail.com
}

\begin{abstract}
Abstrak. Tanah merupakan hasil pelapukan batuan baik secara fisika, kimia, dan organik. Dari sisi keilmuan rekayasa air tanah, tanah memegang peranan yang sangat penting dalam menyimpan air. Kemampuan tanah dalam menyimpan air sesuai dengan ukuran butirannya. Klasifikasi ukuran butiran tanah dapat dibedakan berdasarkan klasifikasi tekstur, dan struktur, yang secara umum dibedakan atas kerikil, pasir, lanau, dan lempung. Setiap klasifikasi tersebut memiliki derajat kejenuhan yang bervariasi.

Penelitian ini menggunakan pendekatan logaritma potensial kapiler $(\mathrm{pF})$ untuk menyatakan energi penahan air di dalam tanah. Kapasitas tanah tidak hanya menahan air namun juga menahan udara sehingga dalam menentukan kelembapan tanah terdapat fraksi cair berupa air dan fraksi gas berupa udara. Tingkat kejenuhan air dan udara di dalam tanah dapat menentukan klasifikasi jenis tanah.

Hasil dari riset ini berupa energi penahan air di dalam tanah yang dikorelasikan dengan parameter tanah lainnya berupa porositas, kadar air, dan derajat kejenuhan dalam bentuk grafik saturasi. Dari hasil pengolahan data, dilakukan interpretasi korelasi derajat kejenuhan air dan udara terhadap jenis tanah.

Hasil yang diharapkan terkait dengan hasil penelitian ini adalah deskripsi distribusi kadar air pada zona tanah tak jenuh air dengan pendekatan logaritma potensial kapiler serta pola perbandingan derajat kejenuhan tanah berdasarkan parameter air dan udara.
\end{abstract}

Keywords: air tanah, derajat kejenuhan, kadar air, $p F$, zona vadose. 


\title{
Characterization of Soil Saturation Degree Based On Capillary Potential Logarithm Approach (pF)
}

\author{
Aris Rinaldi', Reza Adhi Fajar² \& Lilik Eko Widodo ${ }^{3}$ \\ ${ }^{1}$ Master Student of Groundwater Engineering Program, \\ Institut Teknologi Bandung \\ ${ }^{2}$ Doctoral Student of Mining Engineering Program, \\ Institut Teknologi Bandung \\ ${ }^{3}$ Research Group of Earth Resources Exploration, \\ Institut Teknologi Bandung \\ Email: aris.itb@gmail.com
}

\begin{abstract}
Soil is result of weathering of stones either physically, chemically, or organically. From scientific view of groundwater engineering, soil holds a very pivotal role in preserving water. Its ability to retain water is in accordance with the size of its particle that can be classified based on texture and structure, which generally defined to be gravel, sand, silt, and clay. Each of the classification has different saturation degree.
\end{abstract}

This research uses a capillary potential logarithm approach $(p F)$ to declare the water-retaining energy in the soil. Capacity of the soil not only hold back water but also preserve the air so that when determining soil moisture, it contains both water and air. Its saturation level in the soil can determine the soil size classification.

The results of this research is $p F$ that is correlated with other soil parameters in form of saturation graphs. From the result of data processing, we interpret correlation of water and air saturation to soil sizes.

The results that are expected related to this study are the description of water content distribution in the unsaturated soils based on $p F$ and the comparison pattern of soil saturation degree based on water and air parameters.

Keywords: groundwater, $p F$, soil saturation degree, unsaturated soil, water content. 


\section{Pendahuluan (Introduction)}

Derajat kejenuhan tanah merupakan parameter yang berkaitan dengan distribusi kadar air di dalam tanah. Pada umumnya, derajat kejenuhan pada suatu material tanah hanya dikaitkan dengan parameter air saja, dimana derajat kejenuhan merupakan persentase dari ruang pori tanah yang mengandung air.

Parameter kadar air merupakan parameter yang sering diukur pada zona vadose, dimana distribusi kadar air memiliki peran yang sangat penting dalam menentukan derajat kejenuhan tanah. Sementara itu, parameter uap air dan udara juga sangat mempengaruhi derajat kejenuhan tanah, sehingga perlu dilakukan penelitian terhadap parameter udara dalam pengukuran dan perhitungan derajat kejenuhan tanah, khususnya zona tanah tak jenuh air.

\section{Metode (Methods)}

Metode penelitian pada penulisan paper ini menggunakan identifikasi konsep dengan penyesuaian terhadap parameter-parameter yang didapat melalui studi literatur dan pengujian laboratorium, lalu dilakukan perhitungan dan pembahasan terhadap hasil yang berkaitan dengan distribusi kadar air terhadap derajat kejenuhan tanah, baik pada tanah jenuh air maupun tanah tak jenuh air.

Identifikasi konsep dilakukan terhadap peran parameter air dan udara di dalam tanah. Menurut Buckman dan Brady [1], Soepardi [2], air di dalam tanah dapat dibedakan atas air tanah ( $\mathrm{pF} 0$ - 1), air gravitasi ( $\mathrm{pF} 0$ - 1), air kapiler $(\mathrm{pF}<2)$, dan air higroskopis (pF 2.7 - 4.2). Arsyad [3], Guymon [4] menggunakan logaritma potensial kapiler $(\mathrm{pF})$ untuk menyatakan energi penahan air dalam tanah. Adapun persamaan rumus logaritma potensial kapiler $(\mathrm{pF})$ dinyatakan sebagai berikut :

$$
p F=-\log (h)=\log _{10}(-\psi)
$$


Nilai logaritma potensial kapiler $(\mathrm{pF})$ memiliki korelasi dengan nilai pressure head/ tinggi air. Van Genuchten [5] menyatakan bahwa distribusi kadar air dapat dicari dengan menggunakan nilai pressure head $(\psi)$, dengan persamaan rumus sebagai berikut :

$$
\begin{aligned}
& \theta(\psi)=\frac{1}{\left[1+|\alpha \psi|^{n}\right]^{m}} ; \psi<0 \\
& \theta(\psi)=1 ; \psi>0
\end{aligned}
$$

Nilai kadar air pada tanah jenuh air adalah sama dengan nilai porositasnya. Pada tanah tak jenuh air, variasi distribusi kadar air mempengaruhi derajat kejenuhan tanah. Menurut Lambe dan Whitman [6], Fredlund dan Rahardjo [7] derajat kejenuhan tanah dapat digunakan untuk membagi tanah menjadi 3 grup yaitu : tanah kering $(\mathrm{S}=0 \%)$, tanah jenuh air $(\mathrm{S}=100 \%)$, dan tanah tak jenuh air $(0 \%$ $<\mathrm{S}<100 \%$ ). Adapun persamaan rumus umum untuk derajat kejenuhan tanah adalah :

$$
S=\frac{V_{w}}{V_{v}}=\frac{\theta V_{T}}{V_{v}}=\frac{\theta V_{T}}{n V_{T}}=\frac{\theta}{n}
$$

Pada persamaan (4), derajat kejenuhan tanah hanya memperhitungkan parameter air saja sementara parameter udara diabaikan. Kenyataannya, parameter udara juga mempengaruhi derajat kejenuhan tanah. Pengaruh parameter air dan udara pada derajat kejenuhan tanah dapat didekati dengan persamaan (5) berikut :

$$
\mathrm{S}_{\mathrm{w}}+\mathrm{S}_{\mathrm{a}}=1
$$

Metode penelitian karakterisasi derajat kejenuhan tanah berdasarkan pendekatan logaritma potensial kapiler $(\mathrm{pF})$ digambarkan dengan diagram alir berikut ini 


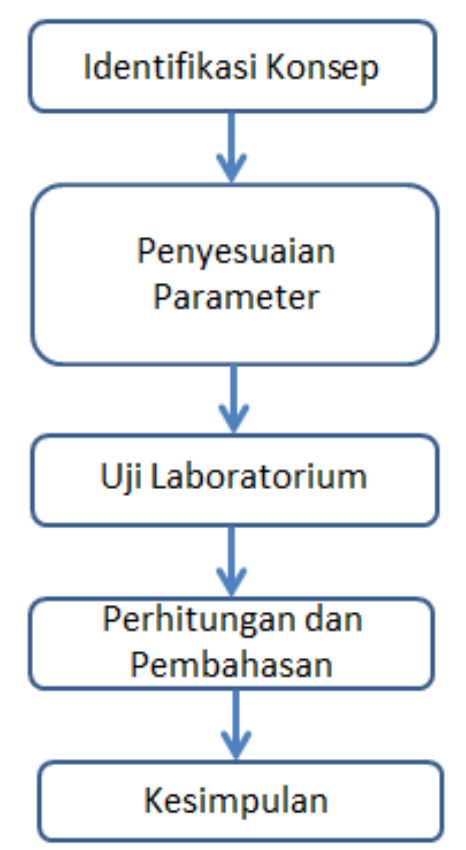

Gambar 1 Diagram alir penelitian

\section{$3 \quad$ Hasil dan Pembahasan (Results and Discussions)}

\subsection{Uji Sifat Fisik Tanah}

Pengujian sifat fisik tanah dilakukan untuk mengetahui parameter fisik pada tanah. Adapun pengujian utama pada uji sifat fisik tanah yaitu uji saringan dan hidrometer, uji kadar air, dan uji koefisien permeabilitas.

Uji saringan menghasilkan pembagian butiran tanah dengan persentase kerikil $42.10 \%$, pasir $57.78 \%$, lanau $0.13 \%$, dan lempung $0.00 \%$. Uji hidrometer tidak dapat dilakukan karna tanah ukuran butir $<0.075 \mathrm{~mm}$ hampir tidak ada yang lolos saringan. Uji kadar air menghasilkan nilai kadar air rata-rata 0.37 , dimana parameter kadar air pada tanah merupakan salah satu sifat yang penting dalam menentukan tingkat kelembapan dan kejenuhan tanah. Pada uji utama lainnya, uji koefisien permeabilitas, didapat nilai $\mathrm{k}=2.625 \times 10^{-3} \mathrm{~cm} /$ detik, dimana koefisien permeabilitas sampel tanah termasuk dalam jenis tanah pasir kasar. 


\subsection{Uji Clustering}

Uji clutering dilakukan untuk mendapatkan material yang sesuai dengan penelitian. Ada dua tahapan dalam uji clustering yaitu uji penghalusan (grinding) dan uji pemisahan (sizing). Dari uji clustering didapatkan tiga jenis ukuran butiran tanah untuk pengujian selanjutnya yaitu tanah setara pasir, setara lanau, dan setara lempung.

\subsection{Uji Retensi Air (pF)}

Tanah hasil pengujian clustering digunakan pada pengujian retensi air $(\mathrm{pF})$. Nilai $\mathrm{pF}$ yang digunakan pada pengujian retensi air yaitu $\mathrm{pF} 1, \mathrm{pF} 2, \mathrm{pF} 2.54$, dan $\mathrm{pF}$ 4.25. Nilai pengukuran kadar air terhadap uji $\mathrm{pF}$ digunakan untuk mendapatkan nilai perhitunngan kadar air dengan menggunakan perhitungan numerik solver, Hapsari, et all [8], Anlauf [9]. Parameterisasi material yang didapat dari simulasi numerik adalah sebagai berikut :

Tabel 1 Perhitungan parameter material setara pasir

\begin{tabular}{ccccc}
\hline No & Parameter & Nilai & Unit & Keterangan \\
\hline 1 & $\theta \mathrm{r}$ & 0.010 & $\%$ & Residual Water Content \\
2 & $\theta \mathrm{s}$ & 0.363 & $\%$ & Saturated Water Content \\
3 & $\mathrm{a}$ & 0.025 & $\mathrm{cmH}_{2} \mathrm{O}$ & Konstanta \\
4 & $\mathrm{n}$ & 4.588 & & Konstanta \\
5 & $\mathrm{~m}$ & 0.782 & & Konstanta \\
\hline
\end{tabular}

Tabel 2 Perhitungan parameter material setara lanau

\begin{tabular}{ccccc}
\hline No & Parameter & Nilai & Unit & Keterangan \\
\hline 1 & $\theta \mathrm{r}$ & 0.024 & $\%$ & Residual Water Content \\
2 & $\theta \mathrm{s}$ & 0.395 & $\%$ & Saturated Water Content \\
3 & $\mathrm{a}$ & 0.017 & $\mathrm{cmH}_{2} \mathrm{O}$ & Konstanta \\
4 & $\mathrm{n}$ & 2.284 & & Konstanta \\
5 & $\mathrm{~m}$ & 0.562 & & Konstanta \\
\hline
\end{tabular}


Tabel 3 Perhitungan parameter material setara lempung

\begin{tabular}{ccccc}
\hline No & Parameter & Nilai & Unit & Keterangan \\
\hline 1 & $\theta \mathrm{r}$ & 0.000 & $\%$ & Residual Water Content \\
2 & $\theta \mathrm{s}$ & 0.304 & $\%$ & Saturated Water Content \\
3 & $\mathrm{a}$ & 0.004 & $\mathrm{cmH}_{2} \mathrm{O}$ & Konstanta \\
4 & $\mathrm{n}$ & 1.586 & & Konstanta \\
5 & $\mathrm{~m}$ & 0.370 & & Konstanta \\
\hline
\end{tabular}

Parameterisasi material tabel 1 , 2, dan 3 didapat dengan menggunakan perhitungan numerik solver dimana hasil pengukuran dan perhitungan memiliki nilai error yang relatif mendekati nol. Nilai parameterisasi material digunakan untuk interpolasi perhitungan distrisbusi kadar air guna mendapatkan nilai derajat kejenuhan pada masing-masing material.

\subsection{Derajat Kejenuhan Tanah}

Variasi distribusi kadar air pada tanah tak jenuh air mempengaruhi nilai derajat kejenuhan air dan udara pada tanah. Hasil perhitungan numerik dan interpolasi terhadap masing-masing material pengujian didapat pola karakterisasi derajat kejenuhan seperti pada grafik-grafik berikut ini:

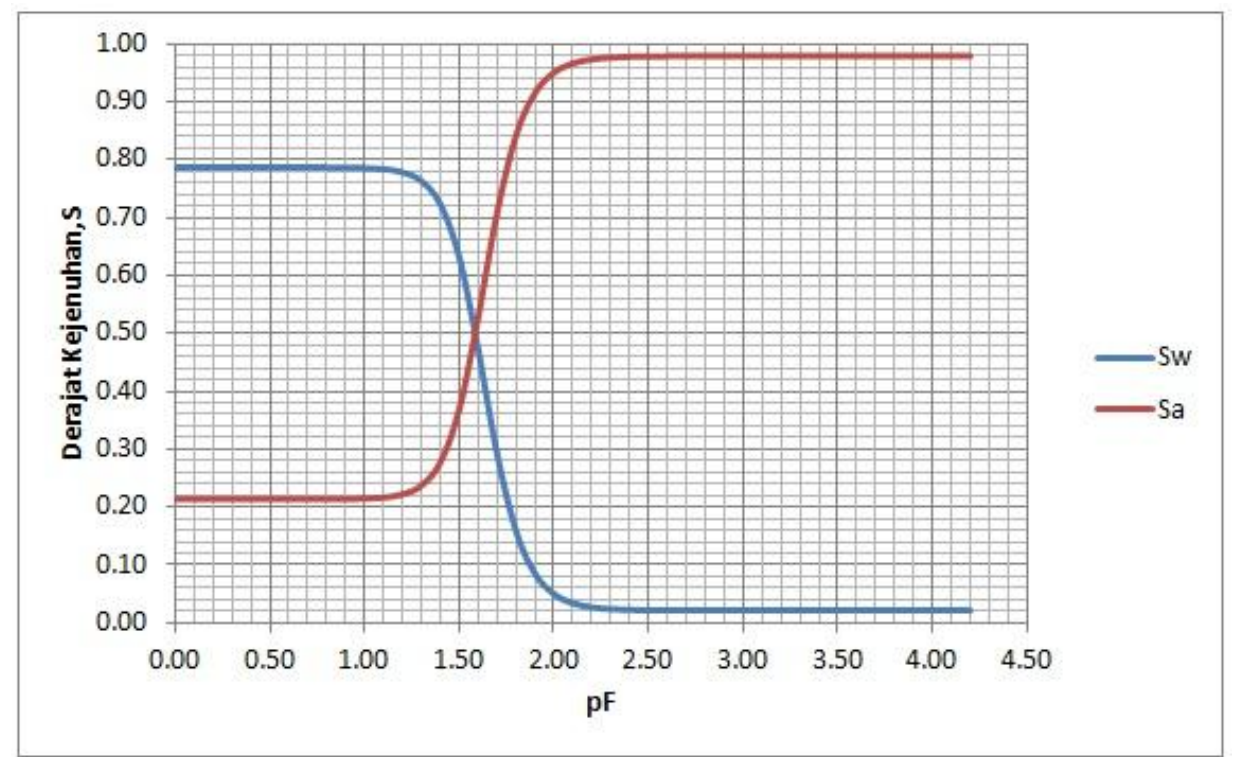

Gambar 2 Grafik korelasi derajat kejenuhan air dan udara pada material setara pasir 


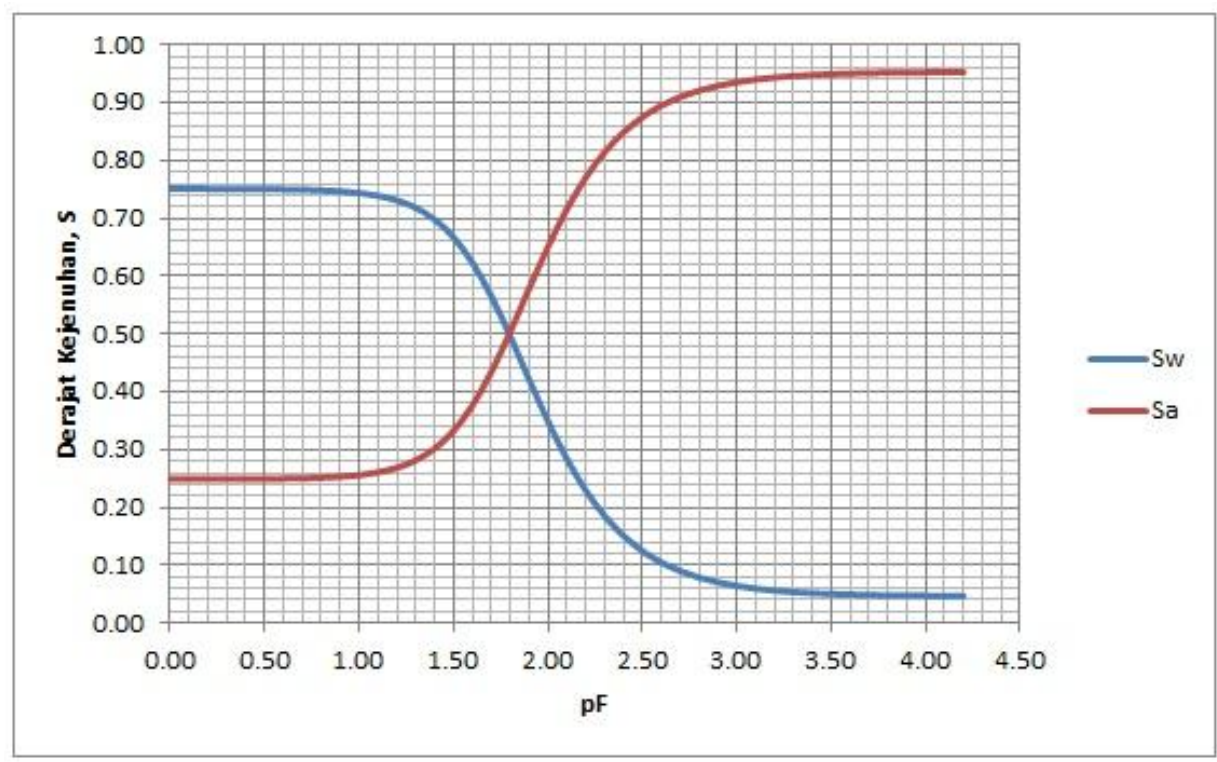

Gambar 3 Grafik korelasi derajat kejenuhan air dan udara pada material setara lanau

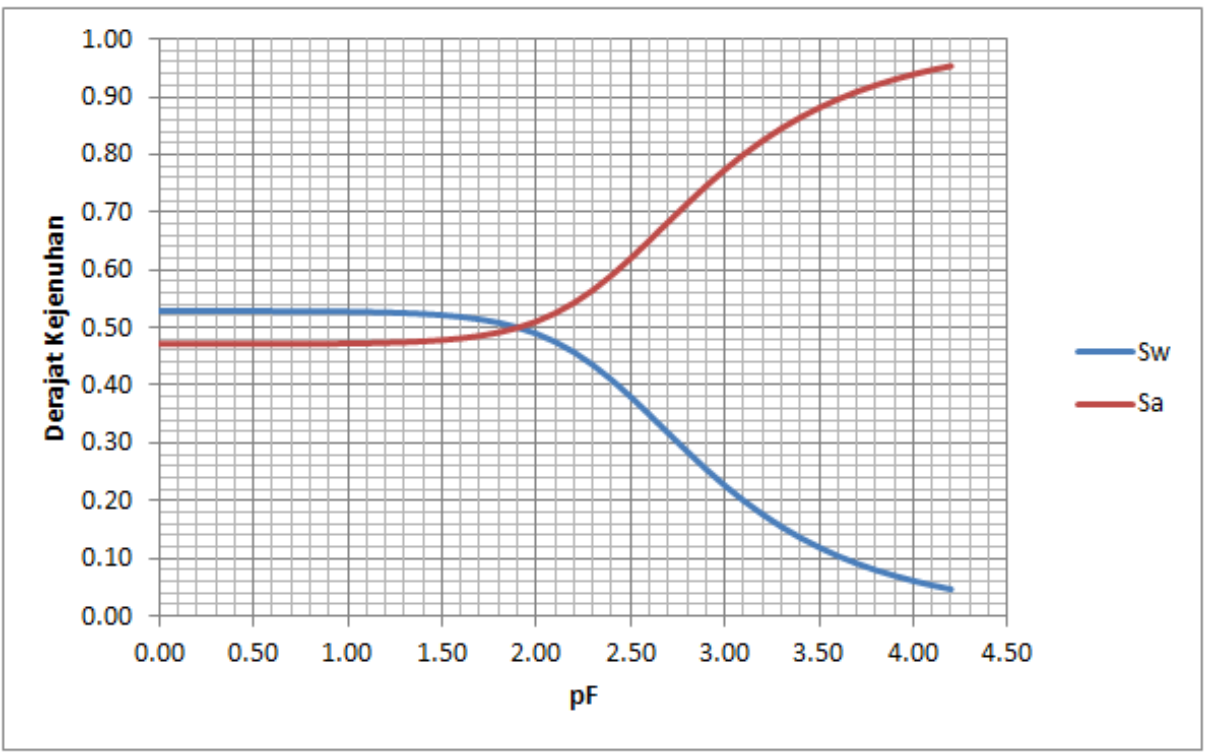

Gambar 4 Grafik korelasi derajat kejenuhan air dan udara pada material setara lempung

Gambar 2, 3, dan 4, merepresentasikan nilai derajat kejenuhan air dan udara pada masing-masing material penelitian. Pada grafik derajat kejenuhan material 
setara pasir, perubahan komposisi derajat kejenuhan air dan udara terjadi pada pF 1.5 - 1.6 dimana pada $\mathrm{pF} 1.5$ nilai $\mathrm{S}_{\mathrm{w}}=0.631, \mathrm{~S}_{\mathrm{a}}=0.369$ berubah menjadi $\mathrm{S}_{\mathrm{w}}=0.472, \mathrm{~S}_{\mathrm{a}}=0.528$ pada $\mathrm{pF}$ 1.6. Pada grafik material derajat kejenuhan setara lanau, perubahan komposisi derajat air dan udara terjadi pada $\mathrm{pF} 1.7$ - 1.8 dimana pada $\mathrm{pF} 1.7$ nilai $\mathrm{S}_{\mathrm{w}}=0.566, \mathrm{~S}_{\mathrm{a}}=0.434$ berubah menjadi $\mathrm{S}_{\mathrm{w}}=0.496, \mathrm{~S}_{\mathrm{a}}$ $=0.504$ pada $\mathrm{pF}$ 1.8. Sementara itu, pada material setara lempung, perubahan komposisi derajat kejenuhan air dan udara terjadi pada $\mathrm{pF} 1.8$ - 2.0 dimana pada pF 1.8 nilai $\mathrm{S}_{\mathrm{w}}=0.508, \mathrm{~S}_{\mathrm{a}}=0.492$, pada $\mathrm{pF} 1.9$ nilai $\mathrm{S}_{\mathrm{w}}=0.500, \mathrm{~S}_{\mathrm{a}}=0.500$, dan pada $\mathrm{pF} 2.0 \mathrm{~S}_{\mathrm{w}}=0.489, \mathrm{~S}_{\mathrm{a}}=0.511$.

Perubahan komposisi derajat kejenuhan dominan air dan udara terjadi pada nilai $\mathrm{pF}$ yang berbeda namun relatif sama pada kondisi air kapiler zona peralihan tanah jenuh air dan tak jenuh air. Nilai derajat kejenuhan air dan udara dipengaruhi oleh distribusi kadar air pada tanah.

\section{Kesimpulan (Conclusion)}

Dari hasil analisis dan pembahasan, dapat disimpulkan bahwa kontribusi parameter udara terhadap derajat kejenuhan pada material pasir silika dapat dibuktikan secara uji laboratorium. Berdasarkan interpretasi grafik didapatkan pola karakterisasi derajat kejenuhan tanah terhadap jenis tanah dalam menyimpan air dan udara. Dari pola yang dihasilkan, dapat dipelajari bahwa semakin kecil ukuran butiran tanah maka nilai derajat kejenuhan air dan udara akan saling mendekati.

Keterkaitan derajat kejenuhan dan kadar air memilki korelasi yang tidak dapat dipisahkan. Pada pengembangan penelitian selanjutnya diharapkan dapat memberikan informasi baru yang berkaitan dengan proses infiltrasi dan konsolidasi terutama pada tanah tak jenuh air. 


\section{Ucapan Terima Kasih (Acknowledgement)}

Kepada LPDP (Lembaga Pengelola Dana Pendidikan) dan pihak-pihak yang terlibat dalam penulisan paper ini, yang tidak dapat disebutkan satu per satu. Semoga menjadi amal jariyah bagi kita bersama. Aamiin.

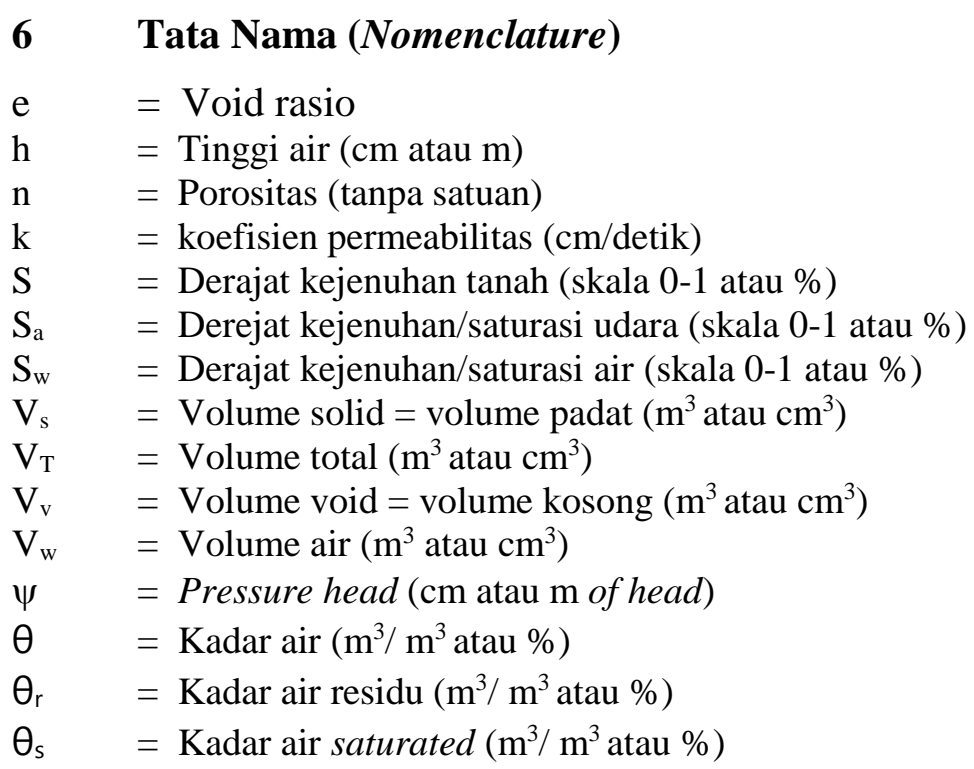

\section{$7 \quad$ Daftar Pustaka (References)}

[1] Buckman, H.O., \& Brady, N.C., Ilmu Tanah. Terjemahan dari The Nature and Properties of Soils, Bhratara Karya Aksara, 1974.

[2] Soepardi, G., Sifat dan Ciri Tanah, Departemen Ilmu Tanah IPB,1979.

[3] Arsyad, S., Konservasi Tanah dan Air, Institut Pertanian Bogor, 1989.

[4] Guymon, G.L., Unsaturated Zone Hydrology, PTR Prentice Hall, 1994.

[5] Van Genuchten, M.Th., A Closed-Form Equation for Predicting The Hydraulic Conductivity of Unsaturated Soils, Soil Sci. Soc. Am. J. 44:892-898, Sept-Oct 1980.

[6] Lambe, T.W., dan Whitman, R.V., Soil Mechanics,John wiley \& Sons, Inc, 1969.

[7] Fredlund, D.G., dan Rahardjo, H., Soil Mechanics for Unsaturated Soils, John Wiley \& Sons, 1993.

[8] Hapsari, C.A., et all., Perhitungan Retensi Air dengan Metode Van Genuchten Menggunakan Macro Visual Basic for Application (VBA), Jurnal Polusi Tanah dan Air Tanah, 2012. 
[9] Anlauf, R., Using The Excel Solver Function to Estimate The Van Genuchten Parameters from Measured pF/Water Content Values. Osnabrueck University of Applied Sciences, www.al.hsosnabrueck.de/anlauf.html, (16 April 2017). 